\title{
Impact of Rustication Joints on Lightweight Insulation in Ventilated Facade Systems
}

\author{
Mikhail Petrichenko ${ }^{1}$, Darya Nemova ${ }^{1}$, Elisaveta Reich $^{1 *}$, Svetlana Subbotina ${ }^{1}$, Faina \\ Khayrutdinova $^{1}$, Rudolf Schilling ${ }^{2}$, Vyacheslav Olshevskyi ${ }^{1}$ \\ ${ }^{1}$ Peter the Great St. Petersburg Polytechnic University, 195251 Polytechnicheskaya Str. 29, St. \\ Petersburg, Russian Federation \\ ${ }^{2}$ Technical University of Munich, D-80333 Arcisstraße 21, Munich, Germany
}

\begin{abstract}
One of the problems of ventilated facades systems is the emission of heat-insulating layer. Emission is a process of separation or removal of material's particles from insulation by virtue of different factors. In this article research of emission of contemporary light weight insulation in system of hinged ventilated façade (VF) with various design is carried out. Impact of design and hydraulic factors on insulation destruction is estimated. Quantitative characteristic of blast air through rustication joints in a vertical channel is given and, consequently, it is possible to determine control point of recirculation zone formation - the beginning of turbulent air flow. Particle's removal in insulation and decline of its properties are most probable in case of tangential stress, that conform to turbulent air flow.
\end{abstract}

\section{Introduction}

In modern construction using of hinged ventilated facades as an enclosure structure has increased. This type of systems is characterized by high heat-shielding properties in comparison with other popular types of walling. One of the aspects of study is the air gap of the system, which characteristics affect heat transfer and durability. [5, 6]

Insulation with a high density, which fiber's emission is relatively low is often used to correct this effect. [7,10] However, this type of insulation is more expensive. Another way to reduce emission of insulation layer is using of wind-shelter membranes. [8] But these membranes also have some deficiencies, such as complication of erection procedure, high ignitability.

Consequently, the question of the possibility of applying lightweight insulation without a wind-shelter membrane in VF systems becomes relevant.

The aim of this study is determination of impact of rustication joints on lightweight insulation in VF systems. [1,3]

Accomplish this aim such challenges were figured out:

1. determination of functional connection between tangential stresses on lightweight insulation's surface and height for VF with various designs.

\footnotetext{
* Corresponding author: lisa reich@mail.ru
} 
2. theoretical estimation of filtration velocity of an air flow in a lightweight insulation.

3. determination of amount of the blast air through rustication joints in a vertical channel and control point of recirculation zone formation.

\section{Literature References}

A large amount of papers are deals with studying of VF systems [1-31]. Characteristics of an air flow in interlayer of VF were analyzed by Diego Angeli, Alessanro Dama [1]. They have examined precision of performance of simplified analytical model of air motion in an air layer in case of free ventilation. Due to this model it is possible to estimate heat transfer in façade systems.

Alexander Meneylyuk, Igor Babij, Ivan Meneylyuk, Artem Gladischuk in their paper $[2,7]$ selected the most appropriate insulation for free-convective air motion in the interlayer of VF. Basing on experimental and static modelings, necessity of applying of compact insulation for its longevity was determined.

\section{Building Characteristics}

Heat conservation in VF system is possible due to its critical part - insulation. In case of its destruction heat loss increase and energy efficiency of the building degrades. Therefore, it is vital to research sources and methods of avoidance of insulation's destruction.

Insulation's emission can be caused by plenty of reasons. Hydraulic factors, such as external air flow and filtration flow, are able to impact on destruction of insulation. In this paper possibility of applying of lightweight spun glassy insulation membrane in VF systems is analyzed. Insulation has a following thermotechnical characteristics:

Dry density $\rho_{0}=2.2 \mathrm{~kg} / \mathrm{m}^{3}$;

Vapor permeability rate $\mu=0.389 \mathrm{mg} /(\mathrm{m} \cdot \mathrm{h} \cdot \mathrm{Pa})$;

Vapor permeability coefficient $\mathrm{s}=10^{-10} \mathrm{~m}^{2}$.

For the estimation apartment building with a maximum allowable height according to Snip 21-01-97 [32] was used without additional agreement (75 meters). It has a following characteristic:

Temperature of the cold surface $\mathrm{T}_{\mathrm{c}}=293 \mathrm{~K}$;

Temperature of the heat surface $\mathrm{T}_{\mathrm{h}}=298^{\circ} \mathrm{K}$;

Head loss coefficient of the rustication joint $\cdot \xi_{\mathrm{r}}=4$;

Head loss entrance coefficient $\xi_{\text {in }}=0.45$;

Width of the air interlayer $\mathrm{h}=0.1 \mathrm{~m}$;

Width of the rustication joint $\delta_{\mathrm{r}}=0.008 \mathrm{~m}$;

Width of the cladding panel $b_{p}=0.6 \mathrm{~m}$.

\section{Estimate of Filtration Velocity}

For checking purposes of impact of filtration flow, filtration velocity in insulation is required to determine:

where:

$$
V_{\text {filtr }}=k \cdot J
$$

$\mathrm{k}$ - filtration coefficient,

where:

$$
k=s \cdot g / v
$$


V -air viscosity;

$\mathrm{J}$ - hydraulic gradient,

where:

$$
J=\Delta P /(\rho \cdot g \cdot L)
$$

L - height of the channel,

$\Delta \mathrm{P}$ - differential head heightwise,

Therefore,

$$
\Delta P=\rho \cdot g \cdot L
$$

$$
V_{\text {filtr }}=k=s \cdot g / v
$$

Estimated filtration velocity for insulation is negligible quantity, that is equal to $10^{-4}$ $\mathrm{m} / \mathrm{s}$. (Figure 1).

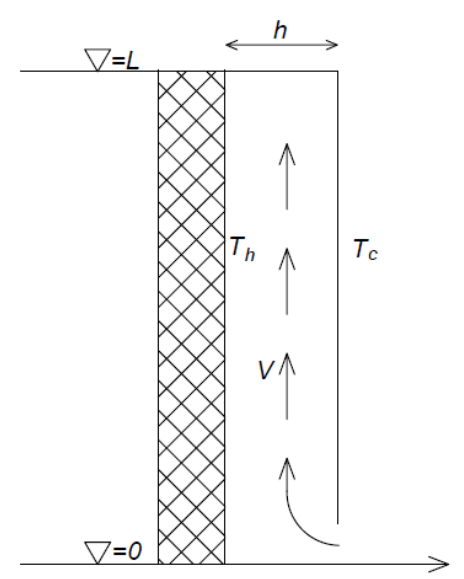

Fig. 1. Diagram of the ideal channel.

\subsection{Ideal Channel}

Ideal channel is a vertical channel that has no rustication joints (Fig.1.). Air flow in this type of construction operates at right angles to temperature head. Air velocity remains constant along the height.

For estimation of the impact of the height on insulation's emission functional connection between tangential stresses and rustication joint's height is determined:

where:

$$
\tau_{0}=\rho \cdot g \cdot R_{h y d r} \cdot J
$$

$\rho$ - ambient density,

g - gravitational acceleration,

$\mathrm{R}_{\text {hydr }}$ - hydraulic mean depth, incidentally $\mathrm{R}_{\mathrm{hydr}}=\mathrm{h}$,

where:

$$
J=\Delta P_{T}(\rho \cdot g \cdot L)
$$

$\Delta \mathrm{P}_{\mathrm{T}}$ - thrust pressure, that is calculated according to the formula:

where:

$$
\Delta \mathrm{P}_{\mathrm{T}}=\xi \cdot \rho v^{2} / 2
$$

$v$ - average velocity of the air flow in the air gap, it is calculated as follows:

$$
v=\varphi \sqrt{1-T_{C} / T_{h}} \sqrt{2 g L}
$$

where:

$$
\varphi=1 / \sqrt{1+\lambda L / h+\zeta}-\text { velocity coefficient, }
$$


$\lambda$ - pipe friction number,

$\xi$ - coefficient of local head losses, in the present case $\xi=\xi_{\text {in }}$,

Therefore:

$$
\Delta \mathrm{P}_{T}=\frac{\xi_{\text {in }}}{1+\xi_{\text {in }}+(\lambda \cdot L / h)} \cdot \gamma \cdot L \cdot\left(1-T_{c} / T_{h}\right),
$$

where $\gamma$ - relative weight,

end formula for determination of tangential stresses in the air interlayer of an ideal channel is as follows:

$$
\tau_{o}=h \cdot \frac{\xi_{\text {in }}}{1+\xi_{\text {in }}+(\lambda \cdot L / h)} \cdot \gamma \cdot\left(1-T_{c} / T_{h}\right),
$$

Consequently, basing on the connection, it can be said that in case of ideal channel gap's height influences on tangential stresses merely by the velocity coefficient. Therefore, tangential stress near the insulation's surface is constant along the air layer.

For the selected building in case of applying VF system without rustication joints tangential stress near the insulation's surface is equal to $9.9 \cdot 10^{-4} \mathrm{~Pa}$

Velocity fluctuation and increasing of tangential stresses in 10 times are specific to turbulent flow.

Motion mode is determined by Grasgoph number:

$$
G r_{h}=\left(g \cdot h^{3} / v^{2}\right) \cdot\left(\Delta T / T_{h}\right)
$$

$G r_{h} \approx \operatorname{Re}_{n}^{2}$

For laminar flow there is criteria as follows:

$$
\operatorname{Re}_{n}^{2}=\sqrt{\left(g \cdot h^{3} / v^{2}\right) \cdot\left(\Delta T / T_{h}\right)},
$$

where $v$ - kinematic viscosity coefficient.

When $\operatorname{Re}_{n} \leq 2300$ - flow mode is laminar.

For the selected channel $\operatorname{Re}_{n}=1290$, that conforms to laminar flow of the air.

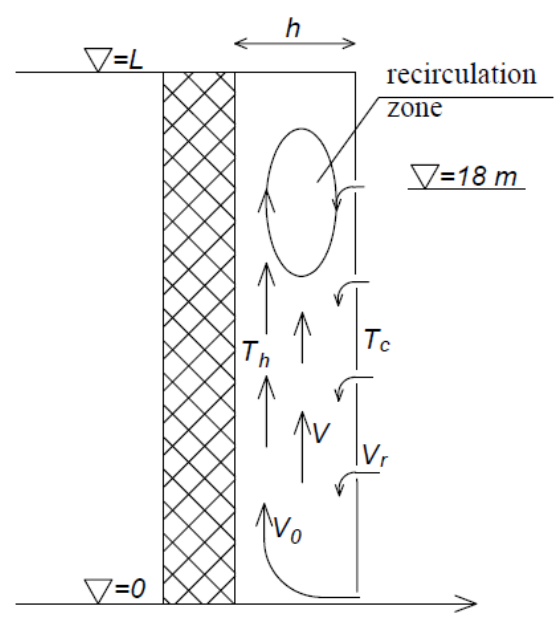

Fig. 2. Diagram of the channel with rustication joints 


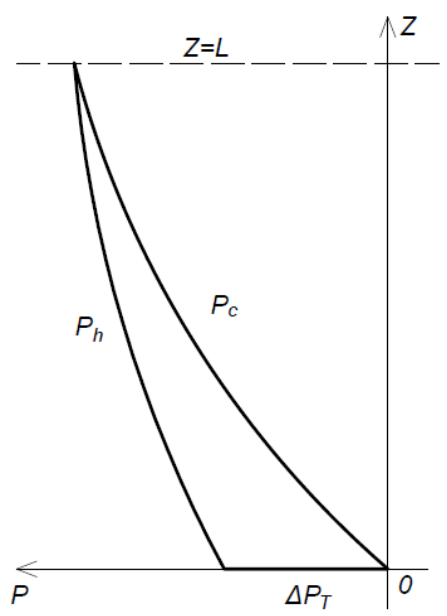

Fig. 3. Pressure difference.

\subsection{Channel with Rustication Joints}

Practically, in most cases channel with rustication joints (gaps between cladding panels) are applied (Fig.2.). They are necessary for temperature deformation compensation. Presence of rustication joints in VF system decrease Froude number almost twice, therefore, velocity coefficient $\varphi$ decreases proportionally. Due to air indraft in joints pressure is not constant along the height, and, with the height extension, the average velocity diminishes until setting to zero. In this moment recirculation zones occur and motion mode becomes turbulent.

Pressure difference (Fig.3.), that is equal to thrust pressure, between hot and cold surfaces at any height is calculated as follows:

$$
\Delta \mathrm{P}_{T}=(1 / n-1 / k) \cdot\left(\frac{g \cdot(L-Z)}{R \cdot T_{o}}\right)^{2} / 2,
$$

where:

$\mathrm{n}, \mathrm{k}$ - polytropic index,

$Z$ - calculated point,

$\mathrm{T}_{0}$ - outdoor air temperature, $\mathrm{T}_{0}=\mathrm{T}_{\mathrm{c}}$,

$\mathrm{R}$ - absolute gas constant.

$$
\Delta \mathrm{P}_{T}=P_{o} \cdot((k-1) / k) \cdot\left(\frac{g \cdot(L-Z)}{R \cdot T_{o}}\right)^{2} / 2
$$

where:

$\mathrm{P}_{0}$ - static pressure at $\mathrm{Z}=0$,

$$
\Delta \mathrm{P}_{T} / P_{o}=((k-1) / k) \cdot\left(\frac{g \cdot(L-Z)}{R \cdot T_{o}}\right)^{2} / 2,
$$

Graph (Fig.4.) depicts quadratic dependency between thrust pressure and height of the channel.

It stands to reason, that maximum pressure difference occurs at $Z=0$, when $Z=L$ pressures are equal. 


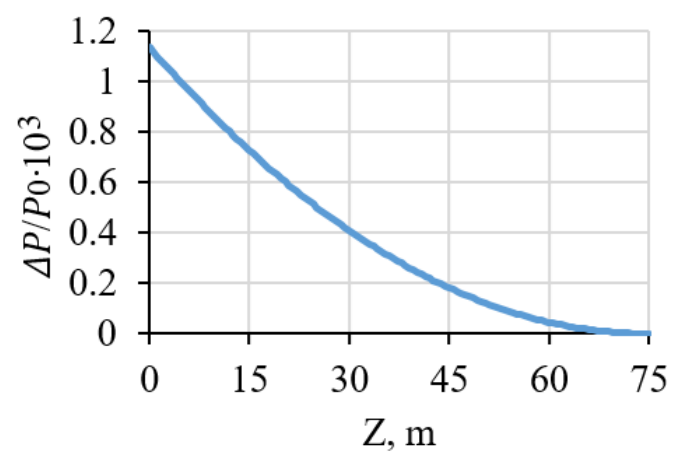

Fig. 4. Dependence $\Delta \mathrm{P} / \mathrm{P} 0$ from the vertical point $\mathrm{Z}$.

Functional connection between thrust pressure and velocity is as follows:

$$
\Delta \mathrm{P}_{T}=\zeta \cdot \rho \cdot v^{2} / 2
$$

Therefore:

where:

$$
v_{r}=\sqrt{2 \cdot \Delta \mathrm{P}_{T} / \zeta_{r} \cdot \rho^{\prime}}
$$

$v_{r}$ - velocity in rustication joint,

Consequently, at $Z=0$ velocity in rustication joint is extreme, dependence between average velocity and vertical coordinate is linear.

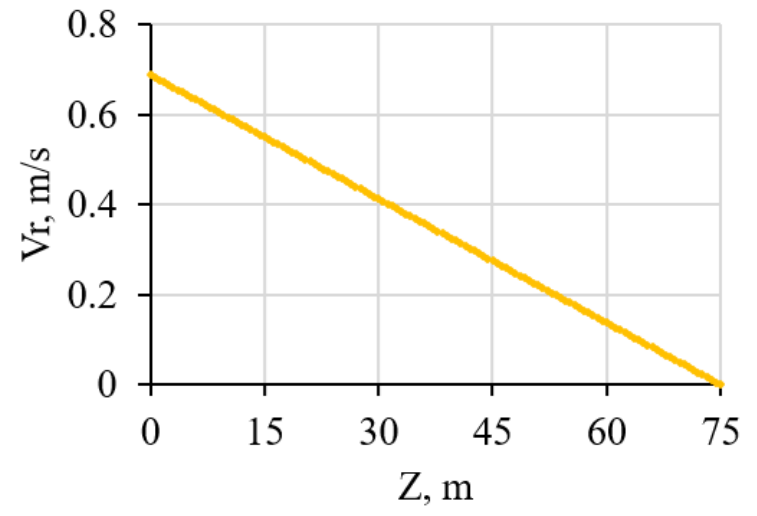

Fig.5. Graph of variance of the average velocity in the joint in relative to the height $Z$.

In the picture (Fig.5.) graph of variance of the average velocity in the joint in relative to the height $\mathrm{Z}$ is represented.

Average velocity without rustication joints can be calculated by the formula:

$$
v_{o}=\varphi \cdot \sqrt{\left(1-\mathrm{T}_{c} / \mathrm{T}_{h}\right)} \cdot \sqrt{2 g L} .
$$

For selected façade average velocity without rustication joints is equal to $1.5 \mathrm{~m} / \mathrm{s}$.

With the height increasing, velocity will be decreasing, due to penetration of the cold air through rustication joints, which motions contradirectionally to the major flow.

Air flow rate is determined as follows: 
where:

$$
\mathrm{Q}=\mathrm{h} \cdot \mathrm{v},
$$

$v$ - air velocity.

Consequently, blast air flow rate through rustication joints can be calculated by the formula:

$$
Q_{c}=\delta_{r} \cdot \sum_{i=1}^{x} v_{r i}
$$

where:

$X$ - number of joints in the channel.

Blast cold air flow rate through rustication joints in the channel for selected building is equal to $0,35 \mathrm{~m}^{2} / \mathrm{s}$.

Hot air flow rate in the channel can be described as follows:

$$
\mathrm{Q}_{\mathrm{h}}=\mathrm{h} \cdot v_{0}
$$
$\mathrm{m}^{2} / \mathrm{s}$.

Therefore, hot air flow rate in the channel of VF systems is constant and equal to 0.15

Height, at which blast cold air flow rate through rustication joints is equal to hot air flow rate, conforms to the beginning of recirculation zone's formation:

$$
\delta_{r} \cdot \sum_{i=1}^{x} v_{r i}=h \cdot v_{o}
$$

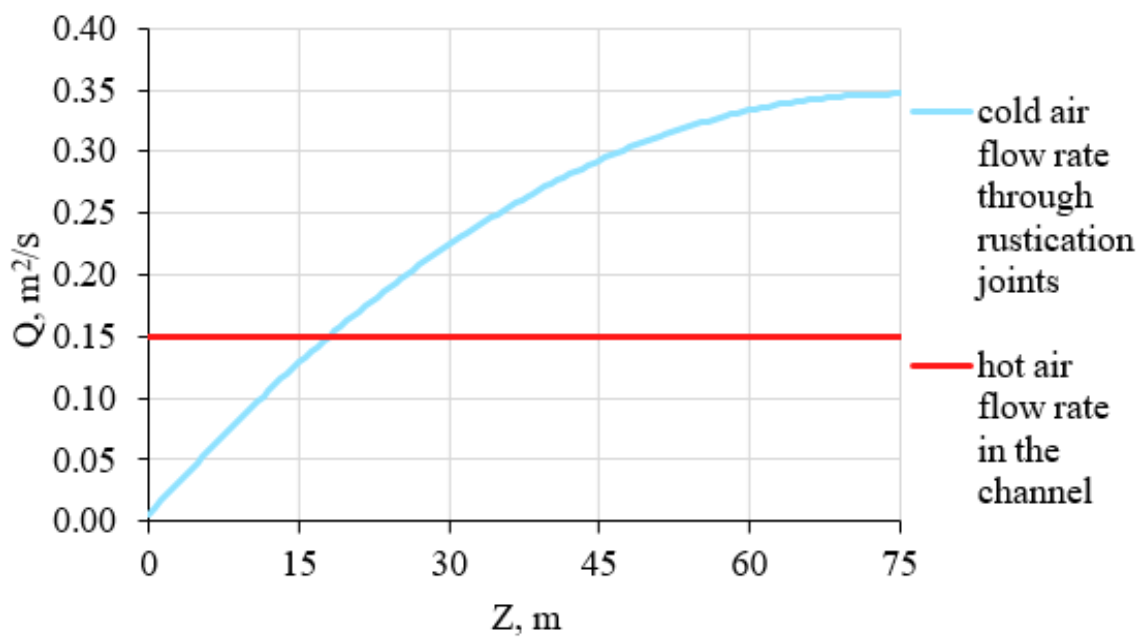

Fig. 6. Dependence between air flow rate and height point of the channel Z.

It can be seen, that at the height $Z \approx 18 \mathrm{~m}$ cold air income through rustication joints derails updraft air movement. By virtue of this penetration, recirculation zones occurs, motion mode is turbulent and tangential stresses near the surface increase abruptly.

Value of decreasing of an average velocity in the air gap of every joint can be estimated from flow equality:

$$
\begin{aligned}
& v_{r} \cdot \delta_{r}=\Delta v \cdot h, \\
& \Delta v=v_{r} \cdot \delta_{r} / h,
\end{aligned}
$$


where:

$\delta_{r}$ - width of rustication joint.

Therefore, total velocity is as follows:

$$
v=v_{o}-\sum_{i=1}^{x} \Delta v_{i}
$$

After point of 18 meters velocity reverse the direction, air motions downward. By virtue of it, façade seizes perform correctly - moment of channel closure (Fig.7).

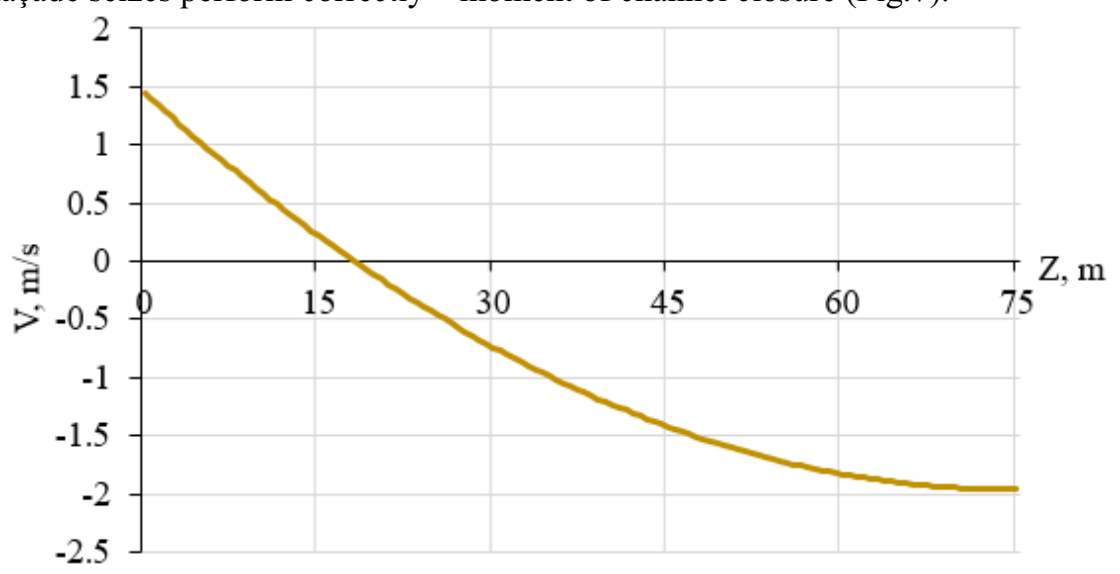

Fig. 7. Dependence between air velocity and height point of the channel Z.

With notice of velocity, tangential stresses for laminar flow can be estimated:

$$
\tau_{L}=\rho \cdot v^{2} / 2 \cdot \pi
$$

For turbulent flow tangential stresses are approximately 10 times as much as in case of laminar flow (Fig. 8):

$$
\tau_{t} \approx 10 \tau_{L}
$$

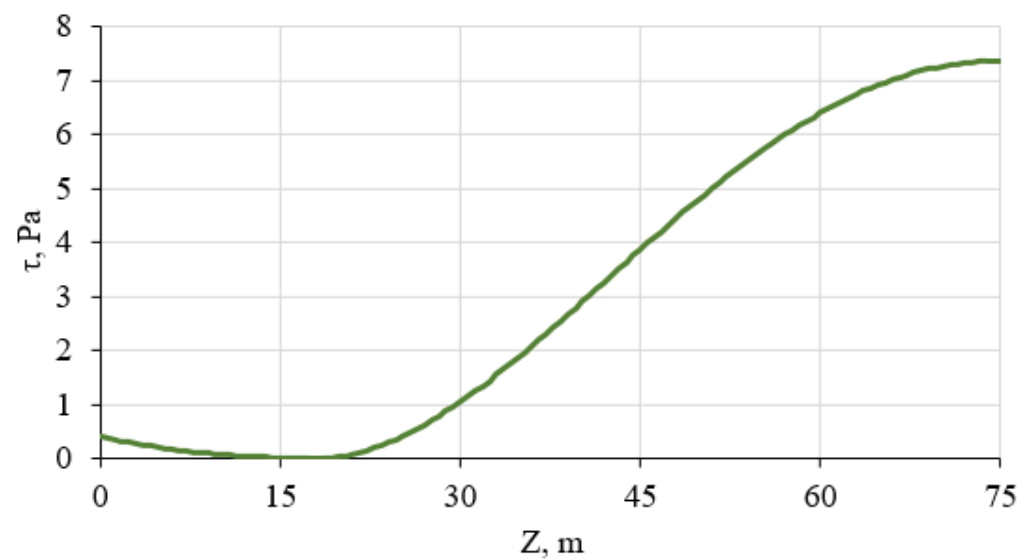

Fig. 8. Dependence between tangential stresses in the channel with joints and height point $Z$.

Tangential stresses in selected channel decrease until point of 18 meters, after that they become increase attaining its maximum of 7,4 $\mathrm{Pa}$ at the height of 75 meters (Fig.8.). 


\section{Conclusions}

Based on these studies, the following connections were identified:

1. Filtration velocity for insulation of VF system was estimated and its value is negligible.

2. For ideal channel tangential stresses near the insulation's surface are constant along the height of the façade, due to laminar flow. For the channel with rustication joints tangential stresses decreases until definite height, and after that, extremely increase by virtue of substitution of the motion mode for turbulent flow.

3. Quantity of the blast cold air through rustication joints of the vertical channel was determined. It afforded to estimate height of the formation of recirculation zones, that was equal to $18 \mathrm{~m}$.

Recirculation zones substitute laminar flow for turbulent motion mode of the flow, thereby increasing tangential stresses in times, that negatively affects insulation in the system.

\section{References}

1. D. Angeli, A. Dama, Energy Procedia, 78, 1537-1542 (2015)

2. A. Meneylyuk, I. Babij, I. Meneylyuk, A. Gladischuk, Suchasni Tekhnolohiyi, Materialy i Konstruktsiyi v Budivnytstvi, 19, 28-33 (2015)

3. C. Popa, D. Ospira, S. Fohanno, C. Chereches, Energ. Buildings, 50, 229-233 (2012)

4. N. Vatin, M. Petrichenko, D. Nemova, Appl. Mech. Mater, 633-634, 1007-1012 (2014)

5. M. Petrochenko, K. Strelets, M. Petrichenko, E. Yavtushenko, Appl. Mech. Mater, 672-674, 567-570 (2014)

6. I. Babij, I. Meneylyuk, Suchasni Tekhnolohiyi, Mat. i Konstr. v Bud., 17, 26-31 (2014)

7. I. Smirnov, E. Shesterova, D. Nemova, M. Petrichenko, Appl. Mech. Mater, 725-726, 130-137 (2015)

8. N. Mingotti, T. Chenvidyakarn, A. Woods, Build. Environ, 46, 807-823 (2011)

9. A. Korjenic, J. Zach, J. Hroudová, Energ. Buildings, 116, 45-58(2016)

10. H. Elarga, M. Carli, A. Zarrella, Energ. Buildings, 104, 97-107 (2015)

11. T. Zadvinskaya, A. Gorshkov, Adv. Mat. Res, 953-954, 1570-1577 (2014)

12. A. Girgidov, Power Tech. Eng., 5 (2015)

13. A. de Gracia, L. Navarro, A. Castell, L.F. Cabeza, Energ. Buildings, 91, 37-42 (2015)

14. M. Nizovtsev, V. Belyi, A. Sterlygov, Energ. Buildings, 75, 60-69 (2014)

15. C. Marinosci, G. Semprini, G.L. Morini, Energ. Buildings, 72, 280-287 (2014)

16. N. Vatin, I. Pestryakov, D. Avdeev, Appl. Mech. Mate.r, 725-726, 454-460 (2015)

17. M. Penić, N. Vatin, V. Murgul, Appl. Mech. Mater., 680, 534-538 (2014)

18. F.M. da Silva, M.G. Gomes, Energ. Buildings, 40, 1553-1559 (2008)

19. A. Hazem, M. Ameghchouche, C. Bougriou, Energ. Buildings, 102, 225-236 (2015)

20. V. Pukhkal, V. Murgul, N. Vatin, Appl. Mech. Mater., 633-634, 1077-1081 (2014)

21. N. Parfentyev, O. Samarin, K. Lushin, S. Paulauskaite, Pap. of conf. of VGTU, 854858 (2008)

22. G. Grinfeld, A. Gorshkov, Vatin N., Adv. Mat. Res, 786-799 (2014)

23. A. Milajić, D. Beljaković, N. Čulić, N. Vatin, V. Murgul, Appl. Mech. Mater., 725726, 1544-1551 (2015)

24. M. Petrichenko, N. Vatin, D. Nemova, V. Olshevskiy, Appl. Mech. Mater., 725-726, 93-99 (2015)

25. T. Zadvinskaya, A. Gorshkov, Adv. Mat. Res., 953-954, 1570-1577 (2014)

26. N. Vatin, O. Gamayunova, Appl. Mech. Mater., 672-674, 550-553 (2014)

27. N. Harmati, Ž. Jakšić, N. Vatin, Appl. Mech. Mater., 725-726, 1572-1579 (2015)

28. N. Vatin, O. Gamayunova, Adv. Mat. Res., 1065-1069, 2159-2162 (2015)

29. Snip 21-01-97 Fire Safety of buildings and structures 